\title{
Identification of a haplotype associated with cholesterol deficiency and increased juvenile mortality in Holstein cattle
}

\author{
S. Kipp, ${ }^{* 1}$ D. Segelke, ${ }^{*}$ S. Schierenbeck, ${ }^{*}$ F. Reinhardt, ${ }^{*}$ R. Reents, ${ }^{*}$ C. Wurmser, $\dagger$ H. Pausch, $\dagger$ R. Fries, $\dagger$

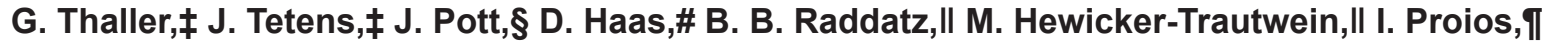 \\ M. Schmicke,ף and W. Grünbergף \\ *Vereinigte Informationssysteme Tierhaltung w.V. (vit), 27283 Verden, Germany \\ †Chair of Animal Breeding, Technische Universitaet Muenchen, 85354 Freising, Germany \\ $\ddagger$ Chair of Animal Breeding, Christian-Albrechts-Universitaet zu Kiel, 24098 Kiel, Germany \\ $\S M a s t e r r i n d \mathrm{GmbH}, 27283$ Verden, Germany \\ \#University Children's Hospital Heidelberg, Division of Neuropediatrics and Metabolic Diseases, Im Neuenheimer Feld 699, 69120 Heidelberg, \\ Germany \\ IIDepartment of Pathology, University of Veterinary Medicine, Hannover, Foundation, Bünteweg 17, 30559 Hanover, Germany \\ ףClinic for Cattle, University of Veterinary Medicine Hannover, Foundation, Bischofsholer Damm 15, 30173 Hanover, Germany
}

\section{ABSTRACT}

Over the last decades, several genetic disorders have been discovered in cattle. However, the genetic background of disorders in calves is less reported. Recently, German cattle farmers reported on calves from specific matings with chronic diarrhea and retarded growth of unknown etiology. Affected calves did not respond to any medical treatment and died within the first months of life. These calves were underdeveloped in weight and showed progressive and severe emaciation despite of normal feed intake. Hallmark findings of the blood biochemical analysis were pronounced hypocholesterolemia and deficiency of fat-soluble vitamins. Results of the clinical and blood biochemical examination had striking similarities with findings reported in human hypobetalipoproteinemia. Postmortem examination revealed near-complete atrophy of the body fat reserves including the spinal canal and bone marrow. To identify the causal region, we performed a genome-wide association study with 9 affected and 21,077 control animals genotyped with the Illumina BovineSNP50 BeadChip (Illumina Inc., San Diego, CA), revealing a strong association signal on BTA 11. Subsequent autozygosity mapping identified a disease-associated haplotype encompassing 1.01 Mb. The segment of extended homozygosity contains 6 transcripts, among them the gene $A P O B$, which is causal for cholesterol disorders in humans. However, results from multi-sample variant calling of 1 affected and 47 unaffected animals did not detect any putative causal mutation. The disease-associated haplotype has an important adverse

Received March 2, 2016

Accepted July 27, 2016.

${ }^{1}$ Corresponding author: sandra.kipp@vit.de effect on calf mortality in the homozygous state when comparing survival rates of risk matings vs. non-risk matings. Blood cholesterol values of animals are significantly associated with the carrier status indicating a codominant inheritance. The frequency of the haplotype in the current Holstein population was estimated to be $4.2 \%$. This study describes the identification and phenotypic manifestation of a new Holstein haplotype characterized by pronounced hypocholesterolemia, chronic emaciation, growth retardation, and increased mortality in young cattle, denominated as cholesterol deficiency haplotype. Our genomic investigations and phenotypic examinations provide additional evidence for a mutation within the $A P O B$ gene causing cholesterol deficiency in Holstein cattle.

Key words: calf survival, haplotype, cholesterol deficiency, hypobetalipoproteinemia

\section{INTRODUCTION}

It is very important to dairy farmers that they successfully raise healthy calves. Diseases during the first weeks of a calf's life not only influence the vitality and well-being of the calf in the short term, but also compromise health and productivity in later life (Correa et al., 1988).

Calf morbidity and mortality is associated with high costs for the farmer, such as compensation for calf losses, the costs for medical treatment, and the costs of raising calves (Mohd Nor et al., 2012). Moreover, calf morbidity and mortality are important animal welfare issues (Mee, 2013). Calf survival is mainly influenced by management factors, but there is also a genetic background for the mortality of young cattle facilitating its inclusion in future breeding strategies (Olesen et al., 2000). In recent years, several recessive haplotypes and a few causative mutations have been discovered in Hol- 
stein cattle (VanRaden et al., 2011; Fritz et al., 2013; McClure et al., 2014), most of them affecting fertility due to increased embryonic mortality. Causative mutations for calf diseases and for the postnatal mortality of calves have rarely been reported (Charlier et al., 2012; Jung et al., 2014; Pausch et al., 2015).

A German breeding organization reported Holstein calves suffering from chronic diarrhea. The affected calves, born without any apparent abnormalities, were underdeveloped, especially in weight, and showed secondary diseases and symptoms, such as pneumonia and edema. Blood analyses revealed lowered cholesterol levels in the range of $15 \%$ of the reference range for cattle $(>1.8 \mathrm{mmol} / \mathrm{L}$; reference laboratory values in Radostits et al., 2007) as hallmark findings. No obvious etiological cause of disease could be identified by attending veterinarians. Diagnostic procedures to identify common viral, bacterial, and parasitic agents affecting calves in their first 6 mo of life yielded negative results. Affected calves did not respond to symptomatic medical treatment and died at ages ranging from 3 wk to 6 mo. Two calves originating from a split embryo, but born and raised in 2 different herds, displayed the same phenotype indicating a genetic background.

Clinical signs in affected calves suggested a disorder of the digestive tract or the lipid metabolism to be responsible for their poor health. Here we report a genetic disorder in Holstein cattle that resembles hypobetalipoproteinemia (HHBL) in humans, caused by mutations in the $A P O B$ gene (Lee and Hegele, 2014). Genome-wide association study (GWAS) and haplotype analysis enabled the identification of diseaseassociated genomic region denominated as cholesterol deficiency haplotype (CDH). In the meantime, the causal mutation for CDH has been detected by Charlier (2016) and Menzi et al. (2016). The occurrence both of the causal mutation and the phenotypic manifestation in other breeds has not been reported yet.

\section{MATERIALS AND METHODS}

\section{Animal Ethics Statement}

Blood samples of affected and unaffected animals were collected by accredited veterinarians. No ethical approval was required for this study. Animal owners had consented to the diagnostic work-up for research purposes and the inclusion of their animals in this study.

\section{Detection of Disease-Associated Region}

Male and female calves with pronounced hypocholesterolemia and chronic emaciation were classified as affected animals $(\mathrm{n}=9)$, of which 5 were referred to the Clinic for Cattle of the University of Veterinary Medicine Hannover Foundation. The affected animals were genotyped with the Illumina BovineSNP50 BeadChip (version 2; 54Kv2; Illumina Inc., San Diego, CA) comprising 54,609 SNP. Genomic data from 21,077 unaffected, control animals, who survived the first year of life, were used from routine genetic evaluation of the German Holstein population including 45,613 SNP (vit, 2016). Chromosomal position of autosomal SNP was determined based on UMD3.1 assembly of the bovine genome (Zimin et al., 2009). Based on this data set, a GWAS was performed as a case-control study including 44,747 SNP, 9 case, and 21,077 control animals. Mixed model analysis of GCTA (version 1.24.7) with $y$ $=a+X b+g+e$ (Yang et al., 2011, 2014) was used to prevent false positives by accounting for population stratification, where $y$ is the phenotype (coded as 1 and 2 for affected and unaffected animals, respectively), $a$ is the intercept, $X$ includes the marker genotypes (coded as 0,1 , or 2 ), $b$ is the additive fixed effect of the candidate SNP to be tested for association, $g$ is the polygenic random effect $\sim \mathrm{N}\left(0, \mathbf{G} \sigma^{2}{ }_{a}\right)$, where $\sigma^{2}{ }_{a}$ is the additive genetic variance and $\mathbf{G}$ is the genomic relationship matrix, and $e$ is the residual. The SNP with $P$-values below $1.116396 \times 10^{-6}$ (Bonferroni-corrected type I error) were considered as significantly associated on a genome-wide level.

\section{Haplotype Analysis}

Haplotypes of 184,188 animals used from the routine evaluation were imputed using Beagle genetic analysis software with default parameters (version 4.0; Browning and Browning, 2009). Due to the identical homozygous region within the affected animals, SNP placed on the Illumina BovineSNP50 BeadChip in the interval from 77.2 to $78.2 \mathrm{Mb}$ on chromosome 11 were used to identify carriers of the haplotype. Due to the fact that the haplotype analyses resulted in homozygous healthy animals indicating an ancestral, healthy version of the haplotype, we additionally accounted for a small haplotype in the interval from 71.8 to $72.4 \mathrm{Mb}$ to distinguish the origin of the 2 identical haplotypes. Furthermore, we carried out an examination of the pedigree including 640,587 animals. Individuals carrying the haplotype at least once, but who did not trace back to the founder of the defective haplotype (the bull MAUGHLIN STORM, born 1991), were set as free animals for the defective haplotype. For the remaining animals who displayed the founder of the defective and the founder of the healthy haplotype, both, in their pedigree, we calculated a conditional probability of carrying the defective haplotype $[p(C D H)]$ as follows: 


$$
p(C D H)=\frac{p(d H)}{p(d H)+p(h H)},
$$

where $p(d H)=$ the kinship to the nearest verified carrier of the defective haplotype and $p(h H)=$ the kinship to the nearest verified carrier of the healthy haplotype. Therefore, the probability depends on the degree of kinship of an individual to each founder.

\section{Copy Number Variant Analysis}

For copy number variant (CNV) analysis, signal intensities obtained from genotyping with the Illumina $54 \mathrm{Kv} 2$ BeadChip are plotted as log $\mathrm{R}$ ratios for cases and (randomly selected) controls within the segment of extended homozygosity by using $\mathrm{R}$ ( $\mathrm{R}$ version 3.1.2). The $\log \mathrm{R}$ ratio is displayed for every individual SNP.

\section{Analysis of Whole-Genome Resequencing Data}

Genomic sequences of 47 animals, consisting of 34 Holstein, 8 Red Holstein, and 5 Red Dairy Cattle key ancestors, were available to an average coverage of $12.76 \times$. Within the scope of this study, one affected Holstein calf with 10.19-fold average coverage displaying the disease phenotype and being homozygous for the disease-associated haplotype was resequenced. Animals were resequenced on Illumina GA IIX, HiSeq2000, and HiSeq2500 instruments as described in Jansen et al. (2013). Reads were mapped to the bovine reference genome assembly UMD3.1 (Zimin et al., 2009) using $B W A$ with default settings (version 0.7.5-r405; Li and Durbin, 2009). The PCR duplicates were marked with PICARD (version 1.98; http://broadinstitute.github. io/picard/). Variants were identified by using the multi-sample variant calling approach provided by Samtools-0.1.19 command mpileup (Li et al., 2009). Phasing and genotype imputation at positions without coverage was performed using Beagle (version 4.0; Browning and Browning, 2009). Within the 48 resequenced animals, $16,928,893$ variable positions were detected among the autosomes where at least the genotype of a single individual differed from the reference genome. The main proportion of the genomic variation consists of biallelic SNP (89.74\%). Within the disease-associated haplotype $(77,274,120-78,290,130 \mathrm{bp}), 6,803$ variable positions were detected including 6,135 biallelic SNP (90.18\%) and 613 biallelic small insertions and deletions (INDEL; 9.01\%). Custom scripts written in Python (Python Software Foundation, version 2.6.6; http:// www.python.org) were used for functional annotation of sequence-based variants in 6 different transcripts
(HS1BP3, LOC100139319, APOB, GDF\%, LOC513245, C20rf43) located within run of homozygosity based on the annotation of the UMD3.1 assembly (Zimin et al., 2009). Of the 161 functionally annotated variants, one polymorphism was located within the $5^{\prime}$ untranslated region, 37 in the promotor region with 1,000-bp length, 97 in the protein coding region, and 26 in $3^{\prime}$ untranslated region of the 6 genes. Due to low-coverage resequencing data implicating inaccurately genotyped polymorphisms (DePristo et al., 2011; Li et al., 2011), we considered variants that were heterozygous or homozygous for the nonreference allele in the affected animal and that were not segregating (homozygous for the reference allele) in the 47 healthy animals.

\section{Survival Analysis}

The database of the central reporting system in Germany, vit in Verden, containing the records of every single calf born with date of birth and death was used to conduct a survival analysis of offspring resulting from 2 different mating types (VanRaden et al., 2011). Animals from mating in which the sire and the maternal grandsire carry $\mathrm{CDH}$ belong to the case group and are considered as risk mating $(\mathrm{n}=19,591)$. The control group consists of animals descending from mating in which the sire do not carry $\mathrm{CDH}$ (= non-risk mating; $\mathrm{n}=2,915,305)$. Survival rate was estimated using Kaplan-Meier estimator as implemented in the $\mathrm{R}$ package 'survival' ( $\mathrm{R}$ version 3.1.2; package for survival version 2.38-1; Therneau and Grambsch, 2000).

The probability that an animal is homozygous for the defective haplotype is calculated by

$$
\frac{1+p}{4(2+p)}
$$

with $p$ being the frequency of the haplotype.

\section{Investigation of Cholesterol Levels}

During the study serum cholesterol concentrations of 250 genotyped animals were measured as described below. The following fixed effect model was fitted to investigate the association between cholesterol concentration and haplotype state:

$$
\mathrm{y}_{\mathrm{ij}}=\mu+\text { haplotype }_{\mathrm{j}}+\mathrm{e}_{\mathrm{ij}},
$$

where $\mathrm{y}_{\mathrm{ij}}$ is the cholesterol level of animal $\mathrm{i}$ with the haplotype state $j, \mu$ is the overall mean, haplotype $e_{j}$ is the fixed effect of the defective haplotype state $(0,1$, 
or 2 copies of the haplotype), and $\mathrm{e}_{\mathrm{ij}}$ is the random residual error term $\left[\mathrm{X} \sim \mathrm{N}\left(0, \sigma^{2}{ }_{e}\right)\right]$. The significance of the differences between the haplotype states is tested with an $F$-statistic (ANOVA).

\section{Description of Phenotype}

With the assistance of local breeding associations and veterinarians, calves originating from a risk mating as defined above and with a suspect phenotype were tested for homozygosity for the suspect haplotype. Five confirmed homozygous haplotype carriers with a suspect phenotype characterized by marked growth retardation, obvious emaciation despite adequate feed intake, and no obvious primary cause for poor growth as of examination by the local veterinarian were referred to the Clinic for Cattle of the University of Veterinary Medicine Hannover Foundation for diagnostic work-up. All calves were female Holstein calves between 3 and 22 wk of age at the time of admission. Upon admission each animal underwent a complete physical examination. Blood samples were obtained by venipuncture of a jugular vein for hematological and blood biochemical examination, and fecal samples were obtained and immediately submitted for bacteriologic and parasitological examination. All calves were furthermore tested for notifiable animal diseases, namely bovine viral diarrhea (BVD, immunofluorescence microscopy and virus isolation), bovine herpes virus 1 (BHV-1, immunofluorescence microscopy, virus isolation, and serology), bluetongue virus (PCR), and Salmonella spp. (culture) in accredited state laboratories.

\section{Blood Hematological and Biochemical Analysis}

Blood samples were obtained at least at the time of the initial examination and in calves that were euthanized immediately before euthanasia; blood was collected in tubes not containing any anticoagulant as well as in vials containing Na-EDTA and vials containing Li-heparin. Samples were analyzed the day of sample collection for the parameters of the standard hematology, blood biochemical panel, and cortisol. Serum and plasma was furthermore stored at $-21^{\circ} \mathrm{C}$ until submitted for the analysis of apolipoprotein (Apo) A1 and cholesterol precursors as described below. The standard hematological analysis was conducted on an automated analyzer (Celltac MEK 6450, Nihon Kohden Europe $\mathrm{GmbH}$, Rosbach, Germany) and included a red blood cell count, packed cell volume, hemoglobin concentration, erythrocyte indices (mean corpuscular volume, mean corpuscular hemoglobin, and mean corpuscular hemoglobin concentration) as well as a white blood cell count combined with a manual white blood cell differential. The standard blood biochemical analysis included the photometric analysis for total protein (biuret reaction), albumin (bromecresol green method), total bilirubin (Jendrassik-Grof method), cholesterol (peroxidase reaction), serum urea nitrogen (urease method), creatinine (picric acid), the enzyme activities of aspartate aminotransferase (malate dehydrogenase reaction), gamma-glutamyl transferase (International Federation of Clinical Chemistry method), glutamate dehydrogenase (International Federation of Clinical Chemistry method), and the electrolytes sodium (ion selective electrode), potassium (ion selective electrode), chloride (ion selective electrode), calcium (methylene blue reaction), phosphorus (ammonium molybdate method), and magnesium (xylidyl blue method). These analyses were conducted on an automated analyzer (Horiba ABX Pentra 400, Fisher Scientific, Pittsburgh, PA). The concentration of the fat-soluble vitamins A and E was analyzed by HPLC (Shimazu RF551, Shimadzu Corp., Kyoto, Japan).

To further explore the cholesterol metabolism in patient calves displaying the phenotype studied in this paper, the plasma cortisol concentration was assayed by means of a chemiluminescence immunoassay (Immulite 1000, Siemens Healthcare GmbH, Erlangen, Germany) in 4 out of 5 calves as an indicator for the synthetic capacity of steroid hormones in study animals. Insufficient amounts of serum from the first calf included in this study precluded analysis of these parameters in one animal. Serum samples of 4 affected calves were furthermore assayed for the concentrations of total cholesterol and cholesterol precursors by GC-MS in the selected-ion monitoring mode on a quadrupole mass spectrometer MSD 5972A (Agilent Technologies, Palo Alto, CA). The following characteristic mass fragments (quantifier/qualifier) were used for quantifica-

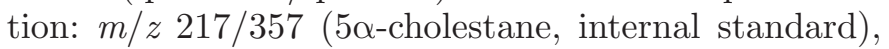
$m / z$ 329/368 (cholesterol), $m / z$ 351/325 (7-dehydrocholesterol and 8-dehydrocholesterol), $\mathrm{m} / z$ 305/306 (cholestanol), $m / z 372 / 343$ (desmosterol), $m / z 255 / 458$ (lathosterol), and $m / z 393 / 498$ (lanosterol).

Serum samples from 4 of the 5 patient calves were assayed for Apo A1 by immunonephelometry (BN ProSpec system, Siemens Healthcare GmbH, Erlangen, Germany). Analysis for bovine Apo A2 and B was attempted, but results are omitted because validation of available test kits for bovine Apo A2 and B was unsuccessful.

Because of a lack of reference values for calves for the parameters sterols, triglycerides (TAG), cortisol, and Apo A1, blood of 6 healthy calves of same age and breed was analyzed for these parameters. 


\section{Necropsy and Histopathological Examination}

All 5 study calves were submitted for postmortem examination and a complete necropsy was conducted within $2 \mathrm{~h}$ after death. The body condition was evaluated based on the subcutaneous and abdominal fat reserves. Cachectic animals were identified by a complete depletion of fat reserves with serous atrophy of the bone marrow or epicardial fat tissue.

Samples for histopathology from the respiratory, gastrointestinal, and urogenital tract, hematopoietic and endocrine organs, musculoskeletal, cardiovascular, and central and peripheral nervous system were fixed in $10 \%$ neutral buffered formalin for $24 \mathrm{~h}$ and embedded in paraffin wax. Three-micrometer-thick sections were mounted on glass slides and stained with hematoxylin and eosin $(\mathbf{H} \& \mathbf{E})$. The liver and small intestine were examined histologically in at least 4 different locations. Light microscopically selected areas of the intestine were examined ultrastructurally with a Zeiss EM 10C electron microscope (Zeiss, Oberkochen, Germany) using the pop-off technique on a formalin-fixed, paraffinembedded, 5- $\mu \mathrm{m}$-thick, H\&E-stained section (Lehmbecker et al., 2014).

\section{RESULTS}

\section{Disease-Associated Region}

Genome-wide association study 9 affected and 21,077 unaffected control animals that were taken from routine genomic evaluation in the German Holstein population (vit, 2016) revealed significant associations with the disease status of 22 SNP located within a $19.22-\mathrm{Mb}$ interval $(64,367,438-83,585,365 \mathrm{bp})$ on BTA 11 (Figure 1A). After Bonferroni correction, the SNP with the strongest association $\left(P=3.9 \times 10^{-66}\right)$ was located at $72,248,536$ bp (ARS-BFGL-NGS-35655). Assuming an autosomal recessive or codominant inheritance of the disorder, all affected animals are supposed to harbor an identical homozygous region containing the causal mutation. Autozygosity mapping within the associated region of BTA 11 revealed a common segment of homozygosity in 9 affected calves encompassing 17 SNP (BTA 11: 77,274,120-78,290,130 bp; Figure 1B). Based on pedigree and genotype information, all affected animals were screened for a common ancestor. Both sire and dam of all the affected animals can be traced back to an internationally popular sire of the Holstein population born in 1991, named MAUGHLIN STORM (Interbull ID HOLCANM000005457798), indicating that this bull is the founder of the disease-associated haplotype.

\section{Haplotype Analysis}

Among 184,188 genotyped Holstein animals, 688 were homozygous and 20,755 were heterozygous for the disease-associated haplotype, resulting in a frequency of $6.01 \%$ in the German Holstein population. However, a large part of the homozygous animals were daughterproven bulls and did not show any phenotypic abnormalities (Figure 1B). In addition, no offspring of these bulls was affected by the disease phenotype, indicating a low specificity of the disease-associated haplotype. The presumed founder of the disease-associated haplotype was not present twice in the pedigree of the homozygous healthy animals. Beside MAUGHLIN STORM, we observed an additional common ancestor in the pedigree of the healthy and affected animals who himself is the maternal great grandsire of MAUGHLIN STORM (Figure 2 ). We presumed that the healthy animals, including the homozygous daughter-proven bulls that are genotyped with the $54 \mathrm{Kv} 2$ chip, inherited at least one copy of the ancestral haplotype without carrying the causal mutation. All of these animals that were false positively identified have an adjacent haplotype in common (BTA 11: $71,838,198-72,437,072 \mathrm{bp}$ ). When interrogating this additional haplotype to exclude false-positives, the frequency of the haplotype decreased to $4.85 \%$ of all genotyped individuals (320 homozygous and 17,247 heterozygous animals). The improved analysis, however, still revealed a few homozygous animals that did not trace back to the founder of the defective haplotype. Therefore, an additional examination for the relationship to the founder of the defective haplotype was implemented. Individuals without any relationship to the founder could not carry the disease-associated haplotype, not even in the heterozygous state. Based on this inspection, 36 animals were excluded as homozygotes, of which one animal switched from a homozygous defective carrier to a homozygous normal state. Seven hundred sixty-six animals carrying the haplotype based on the former procedure were assigned the noncarrier status (Table 1).

The frequency of the disease-associated haplotype significantly increased since the 2000s due to the first mating of animals carrying the causal mutation (Figure 3). The maximum haplotype frequency was seen in 2012 with $6.35 \%$, whereas the carrier frequency was $12.25 \%$. Since 2012, the frequencies in the genotyped German Holstein population declined and are currently estimated to be 4.2 and $7.87 \%$ for haplotype and carrier frequency, respectively.

\section{Analysis of Whole-Genome Resequencing Data}

The CNV analysis based on signal intensities obtained from SNP genotyping does not indicate the 


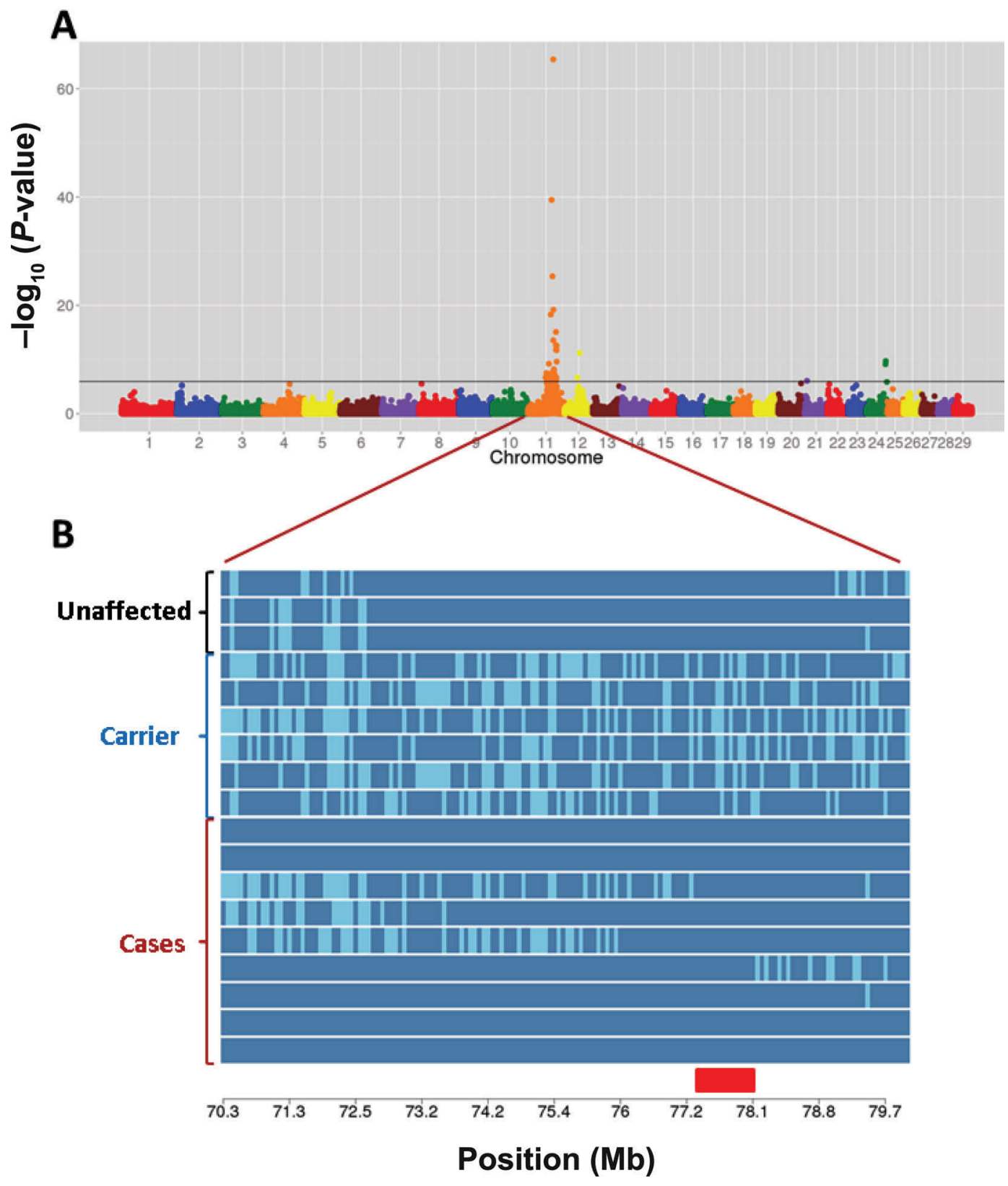

Figure 1. Identification of disease-associated region. Manhattan plot of $P$-values resulting from genome-wide association studies including 44,747 SNP with 9 affected and 21,077 unaffected control animals (A). Homozygosity mapping at BTA 11 in affected animals (cases), direct ancestors of affected animals (carrier), and healthy, unaffected animals. Homozygous SNP are colored in blue (dark gray; AA,BB), heterozygous genotypes are displayed in pale blue (light gray). The location of the cholesterol deficiency haplotype (CDH) is given by the red box. Color version available online.

presence of large structural variants (Supplemental file 1: CNV4CDH; http://dx.doi.org/10.3168/jds.201611118). To identify the putative causal variant, wholegenome-resequencing data of 1 affected calf and 47 key ancestors were analyzed. Except of the calf, which was homozygous for the disease-associated haplotype, none of the 47 other resequenced animals carry the defective haplotype or showed phenotypic abnormalities (e.g., chronic diarrhea or low cholesterol levels). Six different transcripts are located within the 1.01-Mbp disease-associated region. The gene $A P O B$ represents an outstanding candidate gene for the presented disease phenotype. The clinical and blood biochemical phenotype of affected calves in this study resembles the phenotypic appearance of primary HHBL in humans, which is caused by mutations in the $A P O B$ gene 


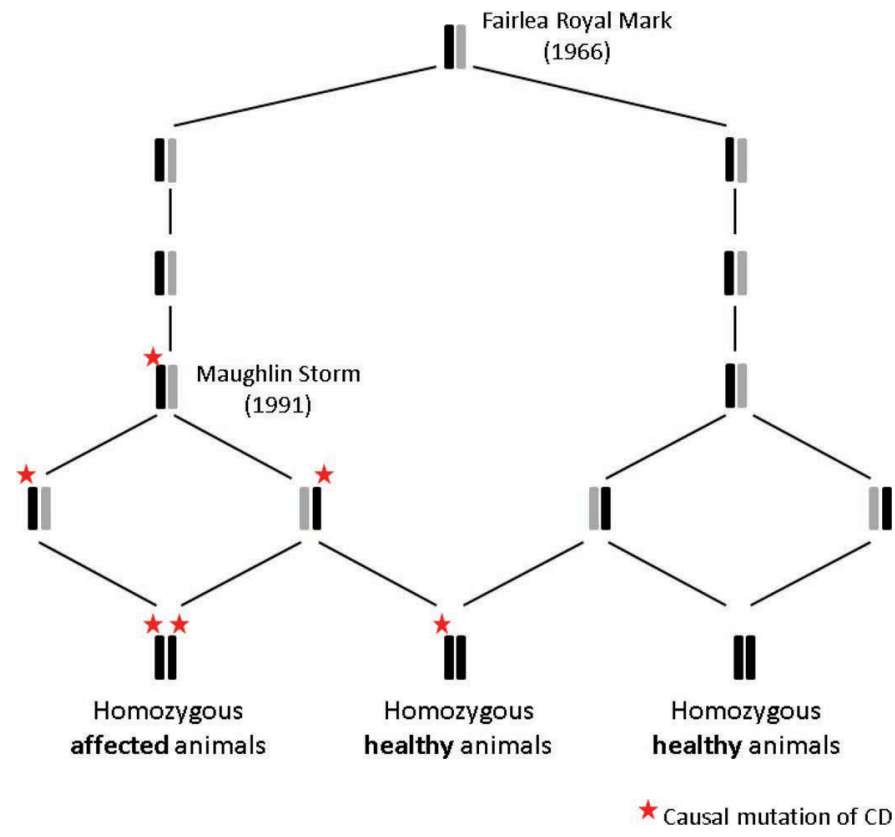

Figure 2. Pedigree of selected homozygous animals. The ancestral haplotype of Fairlea Royal Mark is indicated in black. Other wildtype haplotypes are colored in gray. The star represents the causal mutation of cholesterol deficiency (CD), which presumably occurred in Maughlin Storm for the first time. Affected animals inherit the causal mutation twice due to the inbreeding loop through Maughlin Storm. Healthy animals that are homozygous for the 45K-based haplotype of Fairlea Royal Mark maximally carry the causal mutation in the heterozygous state. Color version available online.

(Lee and Hegele, 2014). Based on multi-sample variant calling among the 48 resequenced animals, 6,803 variants, including SNP and INDEL, were detected of which 161 were located within the genic regions of the 6 transcripts. None of the detected variants could be identified as causal yet due to a lack of compatibility of the detected variants with the pattern of autosomal recessive or codominant inheritance or a lack of association of any of the polymorphisms with the disease phenotype.

Table 1. Haplotype status before and after the examination of the pedigree $^{1}$

\begin{tabular}{lrrr}
\hline & \multicolumn{3}{c}{ Including pedigree information } \\
\cline { 2 - 4 } $\begin{array}{l}\text { Without pedigree } \\
\text { information }\end{array}$ & $-/-$ & $-/ \mathrm{CDH}$ & $\mathrm{CDH} / \mathrm{CDH}$ \\
\hline$-/-$ & 166,621 & 0 & 0 \\
$-/ \mathrm{CDH}$ & 766 & 16,481 & 0 \\
$\mathrm{CDH} / \mathrm{CDH}$ & 1 & 35 & 284 \\
\hline
\end{tabular}

${ }^{1}$ Haplotype analysis revealed 320 homozygous $(\mathrm{CDH} / \mathrm{CDH})$ and 17,247 heterozygous (-/CDH) animals. When interrogating the presence of the founder of the defective haplotype in the pedigree of each genotyped animal, the status of 802 animals switched to another status, resulting in 284 homozygous $\mathrm{CDH}$ and 16,516 heterozygous $\mathrm{CDH}$ individuals. $\mathrm{CDH}=$ cholesterol deficiency haplotype.

\section{Clinical Presentation of Individual Cases}

All 5 animals admitted to the Clinic for Cattle of the University of Veterinary Medicine Hannover had a history of poor growth and progressing emaciation (Figure 4); 3 of the 5 patient calves were reported to have had recurrent episodes of diarrhea, and anorexia with bloat was reported in one case. Four calves have reportedly been treated on the farm of origin with various antimicrobials and antiinflammatory drugs with little or no improvement.

The most remarkable and consistent finding of the initial physical examination was the pronounced emaciation. The general attitude was bright, alert, and responsive in 3 calves and mildly to moderately lethargic in 2. Eyeballs were deeply sunken into the orbita in all calves while the skin tent duration suggested adequate hydration in 3 animals, mild dehydration in one, and moderate dehydration in another calf. All 5 calves were considerably retarded in growth, with a body condition classified as considerably emaciated or cachectic and a dull and rough hair coat. Ages and weights of calves included in this study are summarized in Table 2. All animals were able to stand and ambulate, although one calf showed subtle clinical signs of a radial nerve paresis on one forelimb. No other central or peripheral neurologic abnormalities were identified on neurologic examination. Appetite was good in 2 individuals and mildly to moderately depressed in 3 . Two calves had

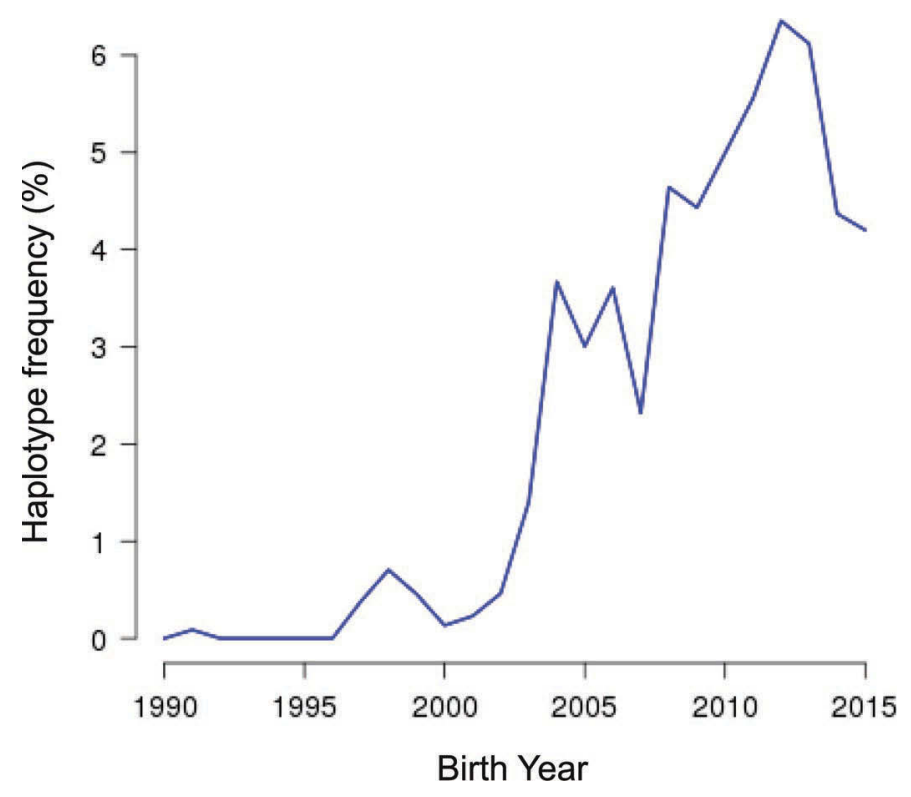

Figure 3. Haplotype frequency in the German genotyped Holstein population. The frequency of the disease-associated haplotype (cholesterol deficiency haplotype) was derived based on the German genotyped Holstein population, consisting of 184,188 animals. Color version available online. 
Table 2. Clinical and necropsy findings of 5 calves that were confirmed homozygous carriers of the cholesterol deficiency haplotype

\begin{tabular}{|c|c|c|c|c|c|}
\hline Case & $\begin{array}{l}\text { Age } \\
(\text { wk) }\end{array}$ & $\begin{array}{l}\mathrm{BW} \\
(\mathrm{kg})\end{array}$ & $\begin{array}{l}\text { Body } \\
\text { condition }\end{array}$ & Clinical findings & Postmortem findings \\
\hline 1 & 20 & 86 & Poor & $\begin{array}{l}\text { Emaciation, growth retardation, lethargic, } \\
\text { moderate feed intake depression, } \\
\text { moderate dehydration, watery diarrhea, } \\
\text { bronchopneumonia, died }\end{array}$ & $\begin{array}{l}\text { - Moderate to severe, multifocal, suppurative, } \\
\text { bronchopneumonia ( } 20 \% \text { of the lung affected) } \\
\text { - Moderate, multifocal degenerative myopathy } \\
\text { with moderate lymphohistiocytic inflammatory } \\
\text { infiltration }\end{array}$ \\
\hline 2 & 22 & 59 & Cachectic & $\begin{array}{l}\text { Emaciation, growth retardation, bright, } \\
\text { alert, good appetite, normal stool, } \\
\text { bronchopneumonia, conjunctivitis, } \\
\text { euthanized }\end{array}$ & $\begin{array}{l}\text { - Moderate to severe, multifocal, } \\
\text { lymphohistiocytic endocarditis and myocarditis }\end{array}$ \\
\hline 3 & 4 & 36.5 & Cachectic & $\begin{array}{l}\text { Emaciation, growth retardation, } \\
\text { bright, alert, good appetite, normal } \\
\text { stool consistency, radial nerve paresis, } \\
\text { bronchopneumonia, died }\end{array}$ & $\begin{array}{l}\text { - Severe, perforating, ulcerative abomasitis } \\
\text { with consecutive severe, diffuse, fibrinopurulent } \\
\text { peritonitis } \\
\text { - Severe, focal, suppurative to necrotizing colitis } \\
\text { - Moderate to severe, multifocal, suppurative } \\
\text { bronchopneumonia (5\% of the lung affected) } \\
\text { - Moderate to severe degenerative changes of } \\
\text { renal tubuli and glomeruli }\end{array}$ \\
\hline 5 & 11 & 50 & Poor & $\begin{array}{l}\text { Emaciation, growth retardation, bright, } \\
\text { alert, good appetite, normal stool } \\
\text { consistency }\end{array}$ & • None \\
\hline
\end{tabular}

loose to watery stool at the time of admission, whereas the feces were of normal consistency in the remaining calves. Rectal temperature was slightly elevated in one animal $\left(39.7^{\circ} \mathrm{C}\right)$, heart and respiratory rate were within normal limits, but 4 of the 5 calves were found to have

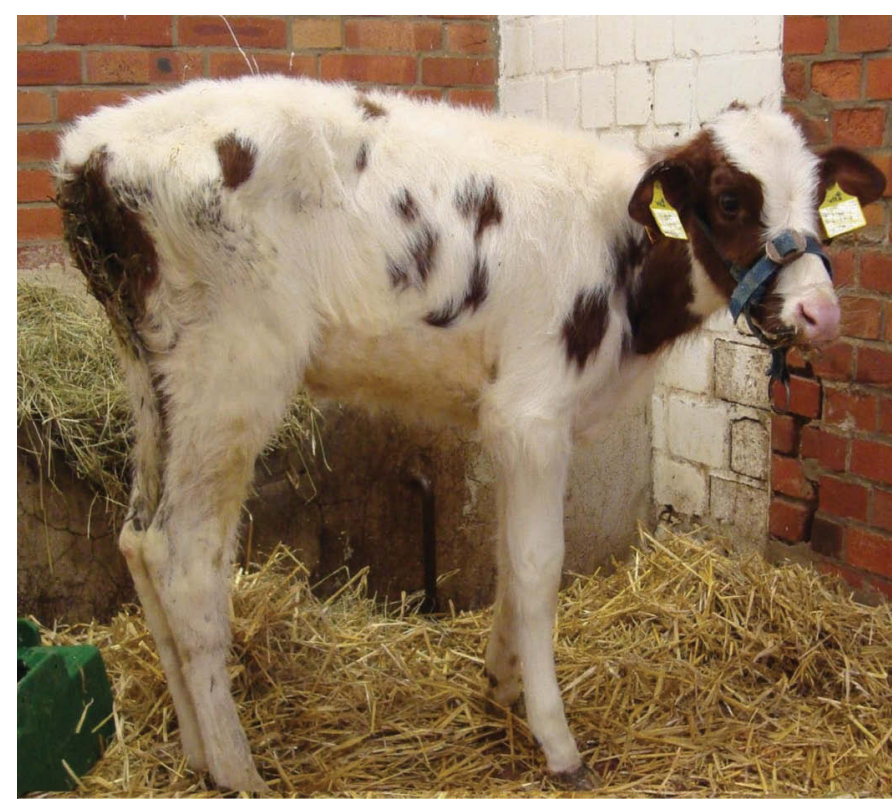

Figure 4. Calf with cholesterol deficiency. Female calf, 22 wk old, $59 \mathrm{~kg}$ of BW, and confirmed homozygous carrier of cholesterol deficiency haplotype ( $\mathrm{CDH}$; case 2 ). Color version available online. mildly to moderately harsh lung sounds on auscultation.

\section{Laboratory Examination}

The results of the hematological and blood biochemical analyses are summarized in Table 3. All calves showed a pronounced leukocytosis and tended to have slightly elevated serum urea nitrogen concentrations. Mild to moderate hypokalemia, with values between 2.5 and $3.1 \mathrm{mmol} / \mathrm{L}$, was diagnosed in 3 calves. Although the red blood cell count was within the reference range in all calves, the mean corpuscular volume and hemoglobin concentrations were below physiological limits in most or all calves (Table 3). Liver enzyme activities in serum were moderately elevated in several calves, with glutamate dehydrogenase above the reference range in $4 / 5$, aspartate aminotransferase in $3 / 5$, and gamma-glutamyl transferase in $1 / 5$ calves. Total bilirubin (TBil) was above the reference range in $3 / 5$ cases. Concentrations of vitamin $\mathrm{A}$ and $\mathrm{E}$ were markedly decreased in 4 calves. One animal had markedly increased concentrations of vitamin $\mathrm{A}$ and $\mathrm{E}$ but was reportedly supplemented with those vitamins by the referring veterinarian shortly before admission. The most remarkable and consistent abnormality of the laboratory standard blood biochemical panel was a pronounced hypocholesterolemia with low-density lipoprotein cholesterol (LDL-C) concentrations below the detection limit in all cases (Table 3). Cortisol con- 
centrations as well as the fraction of different sterols from the total sterol concentration are summarized in Table 3. The values obtained were in the range of values measured in healthy sex- and age-matched control calves. Triglyceride concentrations were substantially lower than values measured in sex- and age-matched control calves (Table 3). Depending on the duration of the hospital stay, between 2 and 8 blood samples were obtained for standard hematological and biochemical analyses. Serum cholesterol concentrations never ex- ceeded $0.31 \mathrm{mmol} / \mathrm{L}$ even in 2 animals supplemented orally with egg yolk concentrate during hospitalization as part of a diagnostic therapy. Apolipoprotein A1 was below the detection limit in all calves.

\section{Fecal Examination}

Fecal samples of all calves were submitted for parasitological and bacteriological examination at least twice. None of the submitted samples was positive for

Table 3. Results of hematological and blood biochemical analysis of 5 calves that were confirmed homozygous carriers of the cholesterol deficiency haplotype $(\mathrm{CDH})$

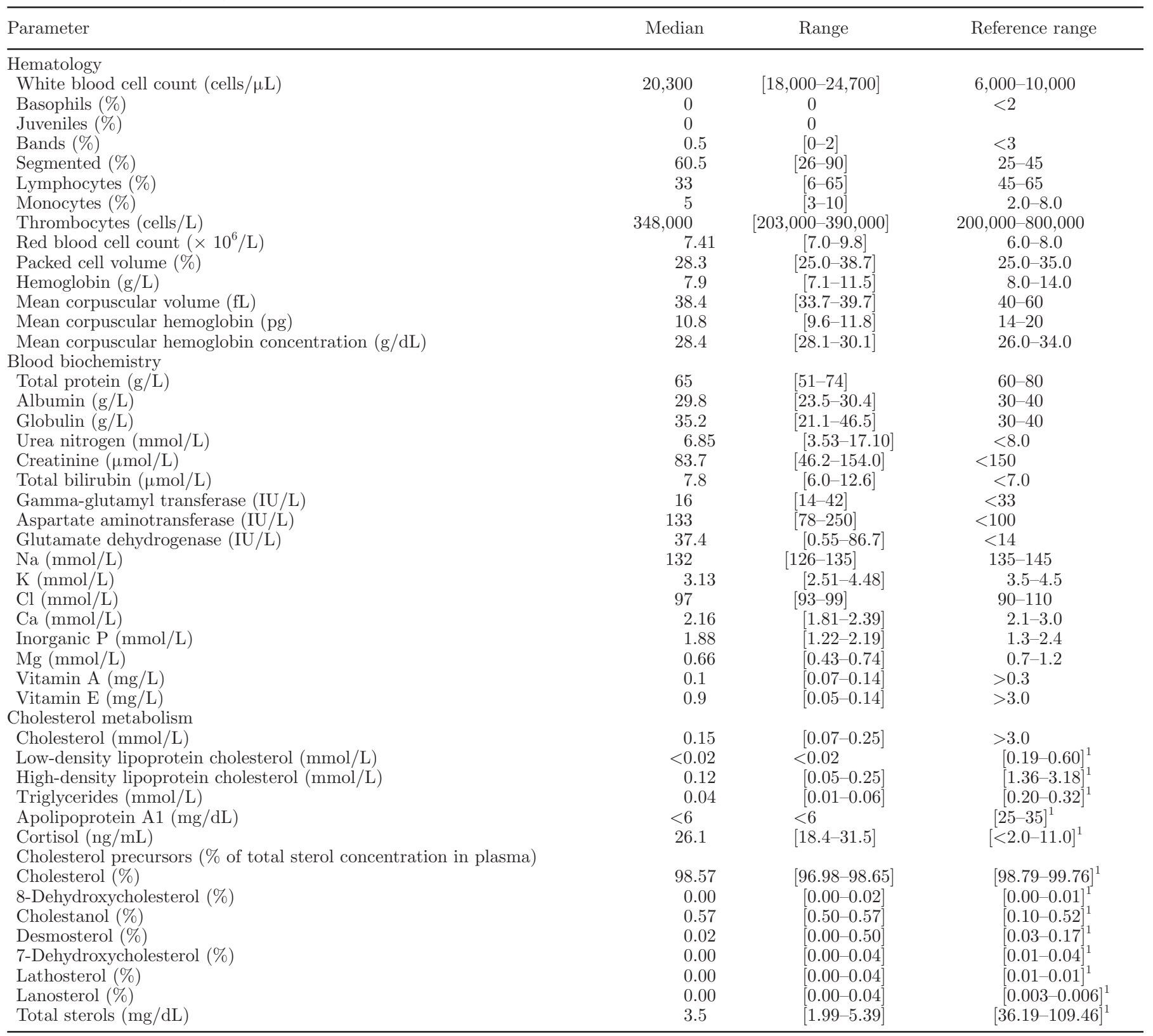

\footnotetext{
${ }^{1}$ Range of values determined in 6 healthy control calves matched for sex, age, and breed in brackets.
} 
endoparasites. In particular, neither Eimeria spp. nor Cryptosporidium spp. could be identified. Salmonella spp. was not cultured in any of the submitted samples.

\section{Further Diagnostic Tests}

Virus isolation of BVD virus and BHV-1 virus was negative in all animals. The PCR for bluetongue virus was also negative in studied animals.

\section{Patient Care and Treatment}

Calves remained in the clinic between $2 \mathrm{~d}$ and $3 \mathrm{wk}$. After initial patient work-up, all animals were given a grave prognosis. Symptomatic treatment for at least $1 \mathrm{wk}$ was initiated in 3 cases. In 2 cases the animal owner agreed to euthanasia within $4 \mathrm{~d}$ of admission. Symptomatic treatment consisted of systemic administration of antimicrobials and NSAIDs in calves with obvious signs of respiratory tract disease. Oral fluid and electrolyte therapy was initiated in 3 calves that either appeared mildly dehydrated or showed electrolyte imbalances. Two calves received intravenous fluid therapy with $0.9 \% \mathrm{NaCl} / 0.5 \%$ glucose solution combined with $\mathrm{NaHCO}_{3}$ as they developed profuse diarrhea resulting in dehydration and acidemia. In 2 calves oral supplementation of cholesterol through administration of egg yolk concentrate $(200 \mathrm{~mL}$ per animal in 12 -h intervals, equivalent to 12 yolks every $12 \mathrm{~h}$ ) over $3 \mathrm{~d}$ was initiated as part of a diagnostic therapy to facilitate differentiation between intestinal cholesterol malabsorption and disturbed cholesterol synthesis as the underlying cause of disease. None of the calves made improvements with the provided supportive therapy. Three calves were euthanized and 2 calves died. The carcasses of all 5 animals were immediately submitted for postmortem examination.

\section{Postmortem Examination of Individual Cases}

All animals showed a very poor body condition, with 4 of 5 animals exhibiting serous atrophy of the bone marrow ("starvation atrophy"; Figures 5 and 6; Table 2 ) and structural fat tissue (Figure 7) and were consequently classified as cachectic. Two of the 4 calves with cachexia displayed severe subcutaneous edema, accentuated over the ventral thorax and abdomen. The abomasum of all animals was filled with moderate amounts of partly digested ingesta. All animals had large amounts of greasy, sticky, bright yellow stool (Supplemental Figure S1; http://dx.doi.org/10.3168/ jds.2016-11118). Additional pathological findings were a moderate to severe, multifocal to confluent, suppurative bronchopneumonia affecting about 5 to $20 \%$ of the lung in 3 animals. One calf additionally showed mild to moderate, multifocal degeneration of the musculature with a moderate lymphohistiocytic inflammatory infiltration (Supplemental file 2: Histology; http://dx.doi. org/10.3168/jds.2016-11118). A severe, ulcerative abomasitis with a perforating lesion resulting in severe, diffuse, fibrinopurulent peritonitis was diagnosed in one calf. This same animal furthermore displayed a severe, focal, suppurative-to-necrotizing colitis and a moderate to severe dilatation of the renal tubuli with intraluminal hyaline and granular casts, multifocal adenomatous proliferation of the tubular epithelium, and a moderate interstitial fibrosis in the kidney. Other pathological findings included a moderate, focal, ulcerative, and fibrinopurulent, subacute ruminitis in one calf and a moderate-to-severe, multifocal, lymphohistiocytic endocarditis and myocarditis in another (Table 2). The one animal not showing cachexia exhibited no additional pathologic findings. The other examined organs were macroscopically and microscopically unremarkable. No signs of lipid accumulation were found in any location of the gastrointestinal tract and electron microscopy did not reveal any ultrastructural changes within enterocytes compared with age- and sex-matched controls. Furthermore, none of the calves showed morphological abnormalities consistent with lipid accumulation in liver tissue.

\section{Survival Rate}

The effect of the defective haplotype on a population scale was assessed by survival analyses comparing the survival rates of descendants from risk mating and survival rates of offspring from non-risk mating. The probability that an animal is homozygous for the defective haplotype is $12.76 \%$ if both sire and maternal grandsire are heterozygous for this haplotype. Male offspring were not considered in the survival analysis because they are mostly redirected to meat production within the first year of life. This would bias the results of the survival analysis. The survival rate of female offspring descending from risk mating $(\mathrm{n}=19,591)$ compared with those from non-risk mating $(\mathrm{n}=2,945,305)$ significantly drops around d 30 after birth (Figure 8, P $<0.0001)$. Within the first year of life, the mortality is $15.6 \%$ for progeny of risk mating and $8.2 \%$ for progenies of non-risk mating, respectively.

\section{Effect on Cholesterol Levels}

During the study we measured serum cholesterol concentrations of 250 genotyped animals. The serum cholesterol concentration was found to be significantly associated with the number of haplotype copies an ani- 

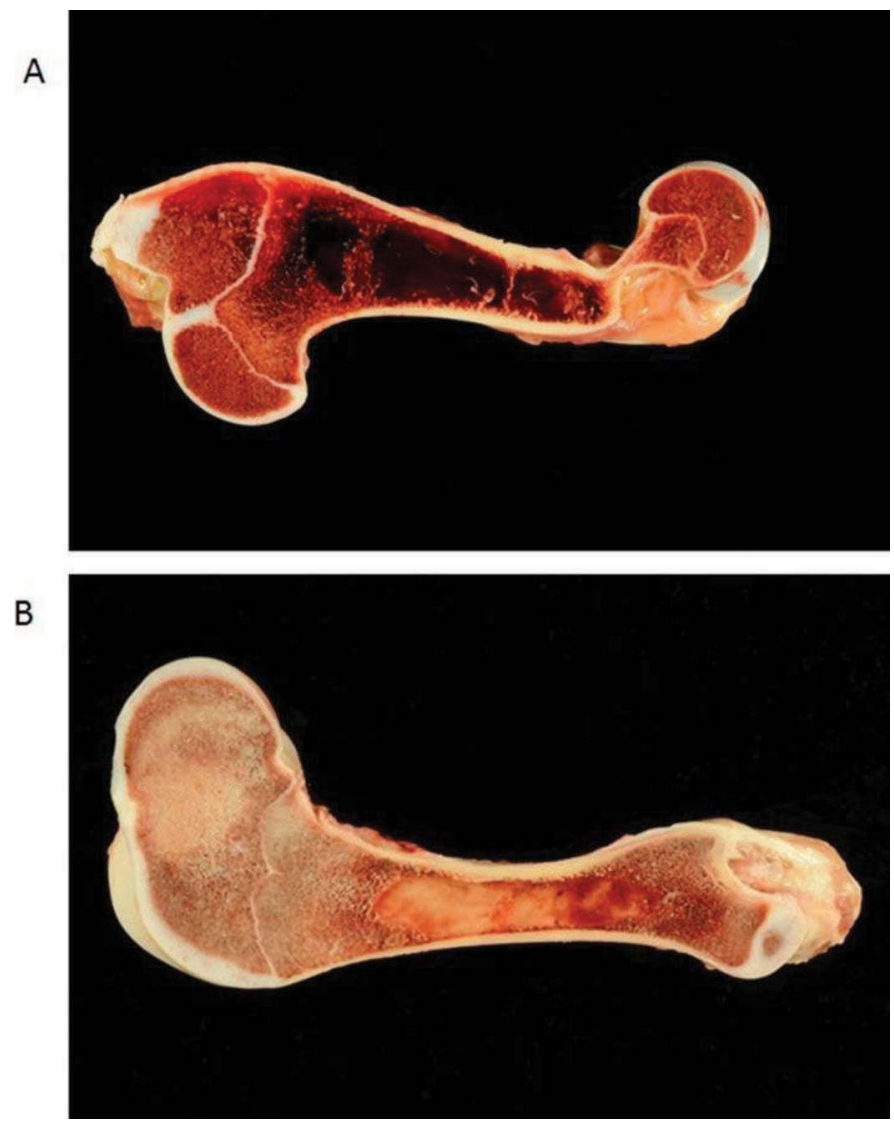

Figure 5. Longitudinal section of the femoral bone. A: Serous atrophy of the femoral bone marrow from animal 4, showing a gelatinous bone marrow transformation (serous atrophy; "starvation atrophy"). B: Longitudinal section of femoral bone marrow of an unaffected control calf. Color version available online.

mal carried. Animals not carrying the haplotype had an estimated mean cholesterol level of $1.82 \mathrm{mmol} / \mathrm{L}$ (SE $0.11 \mathrm{mmol} / \mathrm{L}$ ). Animals with one copy of the haplotype had a significantly lower mean cholesterol level of 1.25 $\mathrm{mmol} / \mathrm{L}$ (SE $0.13 \mathrm{mmol} / \mathrm{L})$. Animals with 2 copies had a significantly lower mean cholesterol level of 0.4 $\mathrm{mmol} / \mathrm{L}$ (SE $0.10 \mathrm{mmol} / \mathrm{L})$. These large differences between noncarrier, carrier, and homozygous defective carrier suggest a codominant inheritance. Due to the association of the disease-associated haplotype and blood cholesterol values, the haplotype was denominated as $\mathrm{CDH}$.

\section{Economic Importance}

Assuming random mating of all bulls, 3,175 animals homozygous for the haplotype are born per year in Germany, given a haplotype frequency of $4.2 \%$ and about 1.8 million Holstein calvings per year. Given an average value of $400 €$ per calf (average lifetime $85 \mathrm{~d}$, raising costs and medical treatment), the economic loss per year in Germany alone mounts up to approximately 1.3 million €.

\section{DISCUSSION}

Genome-wide association study based on 44,747 SNP (45K) and subsequent homozygosity mapping revealed a 1.01-Mb segment of extended homozygosity in affected calves on BTA11 $(77,274,120-78,290,130$ bp), strongly indicating an autosomal monogenic inheritance of this disorder acting in a recessive or codominant manner. The most significant SNP located at $72,248,536$ is about $5 \mathrm{Mb}$ apart from the defective haplotype ranging from $77,274,120$ to $78,290,130 \mathrm{bp}$. It seems that the $45 \mathrm{~K}$-based marker creates a synthetic association (Goldstein, 2009) and cannot tag the defective haplotype (Wang et al., 2010). Previous studies show that such synthetic associations are not unusual for GWAS, particularly if the causal variant occurs at low frequency (Dickson et al., 2010; Jung et al., 2014). However, a total of 22 SNP $(64,367,438-83,585,365$ bp) reached genome-wide significance, encompassing the defective haplotype.

The assumption about the mode of autosomal recessive or codominant inheritance is supported by the presence of a common founder in the pedigree of affected animals due to several inbreeding loops. However, the disorder characterized by cholesterol deficiency is most probably codominantly inherited because calves carrying one copy of the haplotype show intermediate cholesterol values.

Some of the 688 animals, which were identified to be homozygous for the associated 45K-based haplotype, but are healthy, maximally carry the causal mutation in the heterozygous state. Affected progenies emerging from mating of those suspected animals with animals definitely carrying the defective haplotype strongly indicate the heterozygous state. Both homozygous groups, the affected and healthy animals have their origin in a common ancestor passing the identical 45K-based haplotype to their offspring. However, all affected animals revealed the prominent Holstein bull MAUGHLIN STORM on the maternal and paternal side of the pedigree, which does not apply to the homozygous healthy animals who carry the wild type of the haplotype at least once. Most likely, the causal mutation is not included in the $45 \mathrm{~K}$-based SNP panel, suggesting 2 identical haplotypes which differ in the causative variant only, as already shown by Drögemüller et al. (2010) and Jung et al. (2014). Subsequent interrogation of an adjacent haplotype that is not associated with the defective haplotype can reduce the amount of falsepositives. The haplotype frequency was overestimated 


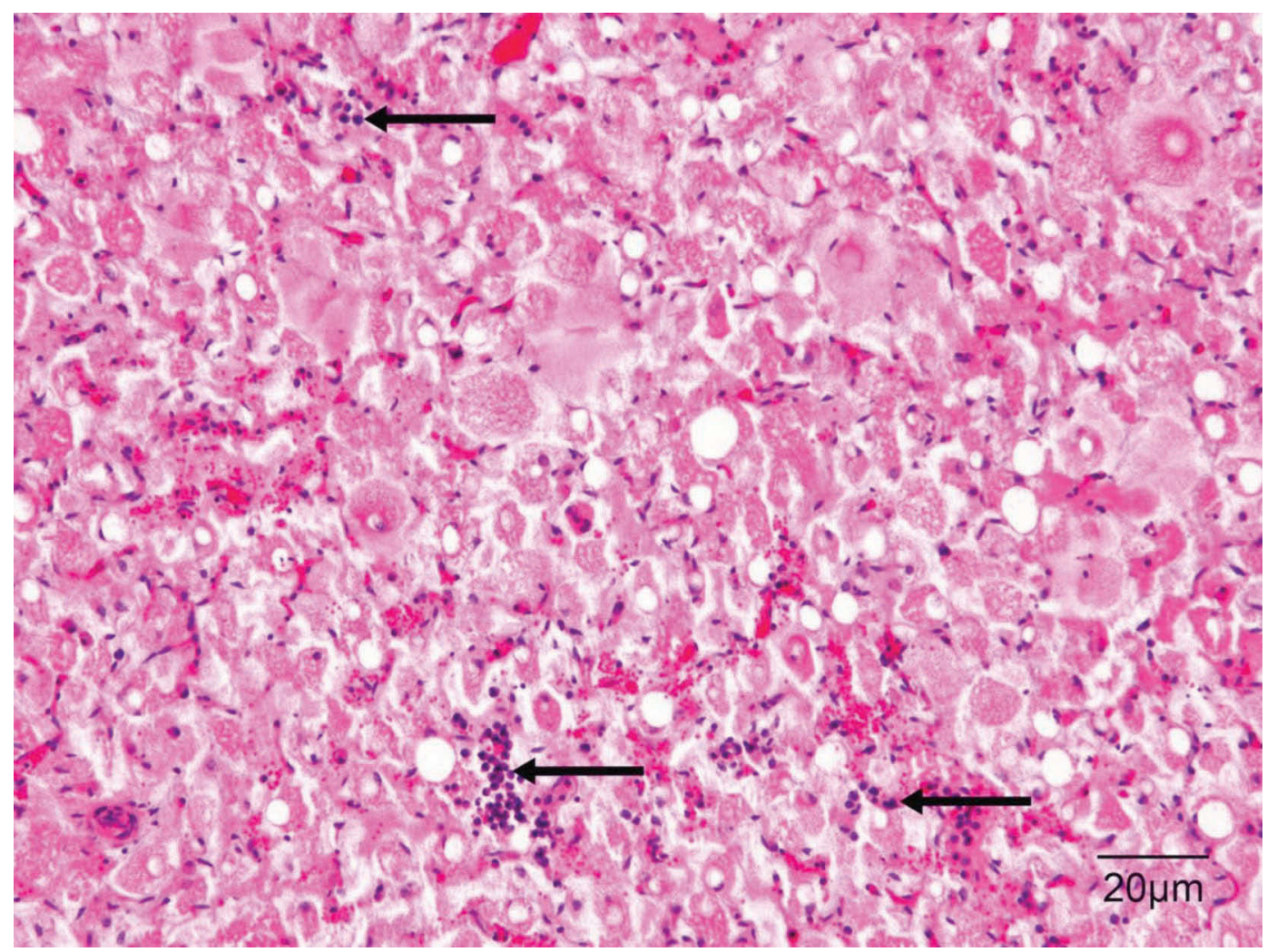

Figure 6. Histology of the femoral bone marrow. Micrograph of the femoral bone marrow from animal 1 . The bone marrow is severely hypocellular with only single, small accumulations of hematopoietic cells (arrows). Adipocytes are atrophied and replaced by an eosinophilic amorphous material. Hematoxylin and eosin stain, $200 \times$. Color version available online.

(from 6.01 to $4.85 \%$ ). After this reassessment, there were still some homozygous, but healthy individuals (e.g., 2 of them were daughter-proven bulls with 526 and 9,704 progenies, respectively). The verification of the presence of the founder for the defective haplotype in the pedigree of these homozygous healthy animals induced a modification of their carrier status. A single individual lost its homozygous status and is actually labeled as noncarrier. This approach did not only increase the power of the haplotype test, but also enabled the calculation of the probability that an animal carries the defective haplotype. Over $98.9 \%$ of the carrier animals have a probability of at least $90 \%$ to carry the defective haplotype (Supplemental file 3: Probability Distribution; http://dx.doi.org/10.3168/jds.2016-11118). The requirements for reliable results are the completeness and accuracy of the pedigree of each animal. The most fatal error would occur if MAUGHLIN STORM is not mentioned in the pedigree of an animal, although the founder is a direct ancestor to this individual. This would automatically lead to a noncarrier status for this animal due to misparentages.

The codominant inheritance and the presumably lethal effect of this disorder let us assume that a mutation affecting the coding region within the disease-associated region would be responsible for the disease phenotype and the corresponding cholesterol deficiency. Therefore, we focused on genic variants resulting from wholegenome resequencing data. Genome-wide resequencing did not reveal any putatively causal variant matching the supposed pattern of codominant inheritance within the 6 transcripts and protein coding genes located in the disease-associated region. The gene $A P O B$ (BTA11: 77,953,432-78,040,408 bp, UMD3.1-annotation; Florea et al., 2011), which is highly expressed in the intestine and liver (Chen et al., 1986) encodes the Apo B responsible for the cholesterol transport in blood. The $A P O B$ represents an excellent candidate gene, particularly due to its causality to HHBL (Lee and Hegele, 2014), a disorder of the cholesterol metabolism. Within the disease-associated region, the bovine genome Bos taurus includes many gaps (around 6\%), especially within the candidate gene $A P O B$ (Zimin et al., 2009). Due to the accumulation of gaps sequences and gene annotation could be incomplete (Herzig and Baldwin, 2009; Florea et al., 2011). It is also likely that the causal mutation could not be captured by next-generation sequencing reads as a result of the incomplete bovine genomic 


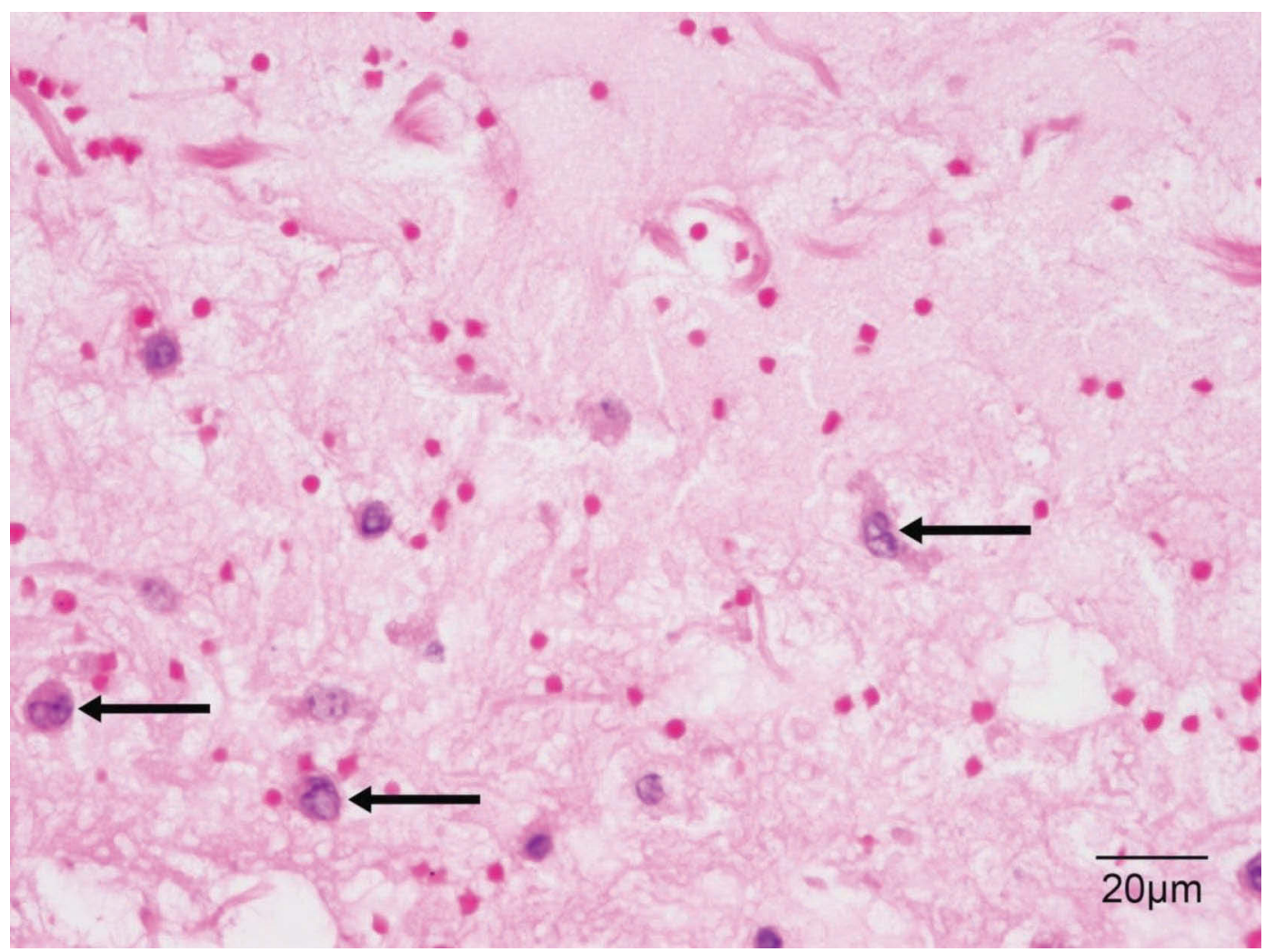

Figure 7. Histology of structural fat tissue. Micrograph of the structural fat tissue of the Hoffa's fat pad from animal 4. Adipocytes are atrophied and replaced by fibrillary to amorphous, eosinophilic material intermixed with single macrophages (arrows). Hematoxylin and eosin stain, 400×. Color version available online.

assembly. Another explanation could be the low average coverage (10.19-fold) of the affected resequenced animal entailing a high probability of inaccurate SNP and genotype calling (Nielsen et al., 2011). The causal mutation is probably not covered by sequence reads of the diseased calf. Because none of the remaining

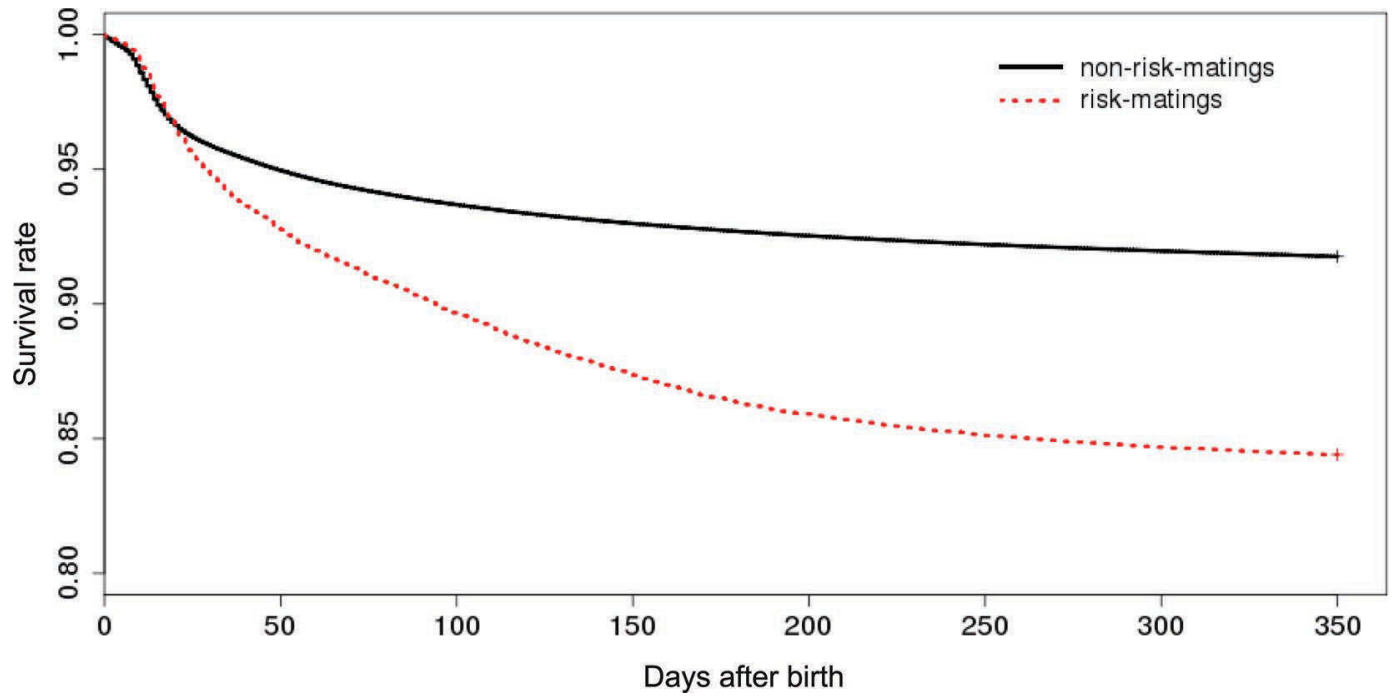

Figure 8. Survival analysis of calves from different mating. Survival rate of calves from cholesterol deficiency haplotype (CDH) risk mating (dotted line; $\mathrm{n}=19,591$ ), where sire and maternal grandsire are carrier for the defective haplotype compared with non-risk mating (solid line; $\mathrm{n}=2,945,305)$. Color version available online. 
resequenced animals are a carrier for the disease-associated haplotype, the causal mutation would remain undetected in the present data set. Deep sequencing of the target, disease-associated region could facilitate the identification of additional low-frequency variants, including the causal mutation.

No SNP or short INDEL analyzed in this study was concordant with the $\mathrm{CDH}$ status of resequenced animals. Therefore, a larger insertion or deletion referred as to a CNV (Freeman et al., 2006) could be causative for the described disorder, which could not be obtained by structural variant analysis performed in this study. Following the standard approach for detecting causal mutations as performed in this study, we could not identify any putative causal mutation for this phenotype. During the preparation of this manuscript, the putative causal mutation was detected by Charlier (2016) and Menzi et al. (2016). The $\sim 1.3$-kb insertion located in the candidate gene $A P O B$ results in a premature termination of the translation and accordingly in a shortened Apo B (p.Gly135FalfsX10; Menzi et al., 2016).

Due to a read length of $\sim 100 \mathrm{bp}$ and an average insert size of 350 to $400 \mathrm{bp}$ of the paired-end reads of the resequenced animals in this study, the power of the detection of such large structural variants is low, particularly for variants that are larger than the insert size (Xi et al., 2010). Larger insert sizes of paired-end reads about several kilobases or the generation of a de novo assembly are the better method for the identification of large CNV. When visually inspecting the read alignment using the Integrative Genomics Viewer (Thorvaldsdóttir et al., 2013), we can see the causal mutation as described by Menzi et al. (2016) (Supplemental file 4: IGV_CDH_mutation; http://dx.doi. org/10.3168/jds.2016-11118).

The phenotype of homozygous haplotype carrier calves discussed in the present report is characterized by poor growth, emaciation, and chronic or recurrent diarrhea from early life on. The hallmark results of the blood biochemical analysis in affected animals were severe hypocholesterolemia with markedly decreased HDL-C concentrations and serum LDL-C levels below the detection limit. Similar results have been reported by Gross et al. (2016) and Saleem et al. (2016). Congenital disturbances of the cholesterol metabolism associated with pronounced hypocholesterolemia in humans are rare diseases. They are divided into disorders resulting from defects of the cholesterol biosynthesis pathway and disorders resulting from a defective cholesterol transport in the body. Disorders of cholesterol biosynthesis result in congenital malformation syndromes in humans and animals with the Smith-Lemli-Opitz syndrome being the most frequent human disorder.
Other disorders with much lower incidence rates are the Conradi-Hünermann syndrome, desmosterolosis, and lathosterolosis. These conditions are caused by deficiencies or malfunction of enzymes required for the pathway of the cholesterol synthesis and are characterized by hypocholesterolemia combined with an elevation of the substrate of the missing or malfunctioning enzyme (Porter, 2008). The sterol analysis conducted as part of the present study revealed that hypocholesterolemia occurred without accumulation of any cholesterol precursor that would be suggestive of disturbed cholesterol biosynthesis. Furthermore, congenital malformations that are common in patients of other species affected by disorders associated with disturbed cholesterol biosynthesis were not observed in any of the individual cases described here. We therefore deem a congenital defect of the cholesterol biosynthesis an unlikely cause of the phenotype reported here.

Hypocholesterolemias in humans resulting from inherited defects of the cholesterol transport in blood are due to inadequate synthesis or secretion of carrier proteins that are required to transport cholesterol molecules in blood. So-called apolipoproteins form the structural proteins of lipoproteins allowing to transport lipophilic cholesterol and TAG in hydrophilic blood. Liver and gut tissue synthetize Apo B that binds cholesterol to form LDL-C and very low density lipoprotein cholesterol to transport cholesterol hematogenously from the site of absorption (gut) or synthesis (liver) to the various sites of utilization for energy production, storage, membrane assembly, or steroid hormone production (Marcovina and Packard, 2006). The reverse transport of excess cholesterol from the periphery to the liver where it can be excreted in bile is mediated through Apo A1 that binds cholesterol to form high density lipoprotein cholesterol (HDL-C). Several inherited defects of the synthesis or secretion of Apo that are associated with hypocholesterolemia have been recognized in humans. Defects associated with subnormal production or secretion of Apo B received particular attention when studying the phenotype in calves reported here not only because the $A P O B$ gene encoding Apo B is an attractive candidate gene according to the presented whole genome resequencing data, but also because of striking similarities between affected humans and calves in the clinical and blood biochemical phenotype.

Homozygous carrier calves all had markedly decreased concentrations of HDL-C, consisting of cholesterol bound to Apo A1 and concentrations of LDL-C consisting of cholesterol bound to Apo B that were below the detection limit. The analysis of serum Apo A1 yielded concentrations below the detection limit in all affected calves, which could be suggestive of a congenital Apo A1 deficiency. Primary congenital Apo A1 deficiency 
has been recognized in human medicine; however, clinical and serum biochemical features of this condition in humans differ considerably from clinical and blood biochemical findings in calves examined in the present study. Human patients affected by congenital Apo A1 deficiency were hypocholesterolemic but had normal or even elevated TAG and LDL-C concentrations (Santos et al., 2008). Furthermore, these patients do not typically show intestinal malabsorption of fat with ensuing diarrhea and deficiency of fat-soluble vitamins as it was observed in the calves in this study. Based on these discrepancies we deem a primary deficiency of Apo A1 an unlikely etiological cause in calves with $\mathrm{CDH}$. It is probable that the subnormal Apo A1 concentrations that were observed here are the result of a secondary downregulation of the Apo A1 secretion due to marginal amounts of circulating cholesterol. Apo secretion is not only dependent on the rate of synthesis but is also regulated through intracellular degradation of the newly synthetized protein depending on the availability cholesterol molecules to bind (Whitfield et al., 2004).

Inherited human disorders associated with deficiency Apo B are termed as hypobetalipoproteinemias (HHBL). Inherited primary HHBL are the homozygous HHBL caused by an $A P O B$ gene defect, resulting in the synthesis of truncated and thus malfunctioning Apo B and abetalipoproteinemia, a disorder caused by a mutation of the MTP gene encoding the microsomal triglyceride transfer protein (Lee and Hegele, 2014). Both mutations cause phenotypically indistinguishable diseases with striking similarities with the phenotype of affected calves presented here. However, both human conditions can be differentiated by their inheritance pattern. Whereas the recessive inheritance pattern of abetalipoproteinemia is associated with normal cholesterol concentrations in heterozygous individuals, the autosomal codominant inheritance of HHBL is associated with half-normal cholesterol concentrations in heterozygous individuals that are clinically healthy, as is the case with calves that are heterozygous carriers of CDH (Lee and Hegele, 2014).

Patients with HHBL have a serum chemistry profile characterized by severe hypocholesterolemia with undetectable LDL-C and Apo B concentrations as well as marginal concentrations of TAG and fat-soluble vitamins $\mathrm{A}$ and $\mathrm{E}$, all findings that are consistent with the serum chemistry profile of calves homozygously carrying CDH (Burnett and Hooper, 2015). A further clue suggesting that a cholesterol transport rather than a cholesterol synthesis malfunction is the underlying cause of $\mathrm{CDH}$ is the failure of dietary cholesterol supplementation in increasing serum cholesterol concentrations. Increasing the dietary cholesterol supply through addition of nutrients rich in cholesterol such as egg yolk is part of the recommended treatment for patients with Smith-Lemli-Opitz syndrome and other cholesterol synthesis disorders (Porter, 2008).

Individuals with HHBL and even in heterozygous carriers were reported to have an increased risk to have elevated liver enzyme activities and serum TBil concentrations (Burnett and Hooper, 2015). Increased occurrence of hepatic lipidosis has been reported in patients with HHBL beyond their second decade of life. The underlying mechanism appears to be the result of assembly of very low density lipoprotein cholesterol particles smaller than usual from truncated Apo B molecules which results in TAG accumulation in the liver (Tarugi and Averna, 2011). In the present study, we found increased liver enzyme activity and TBil concentrations in several calves but none of the animals were found to have developed hepatic lipidosis according to results of the postmortem examination, which might be attributable to the young age of the animals at the time of death or euthanasia (Burnett and Hooper, 2015).

The clinical presentation of calves homozygously carrying the $\mathrm{CDH}$ are growth retardation, emaciation, and intestinal malabsorption resulting in chronic or recurrent diarrhea. In humans, primary HHBL can cause a wide range of clinical features, but growth retardation, steatorrhea, and malnutrition are common (Tarugi and Averna, 2011).

In advanced stages, neuropathies, ophthalmopathies, and myopathies associated with neurological disturbances resulting from chronic deficiency of fatsoluble vitamins can occur. The severity of the clinical presentation of HHBL can be controlled by rigorously maintaining a low-fat diet and supplementation of medium-chain TAG and fat-soluble vitamins (Tarugi and Averna, 2011). Interestingly, no typical signs of lipidsoluble vitamin-deficiency could be detected in calves in this study, although one calf showed a multifocal degeneration of the musculature, a well-known sequela in vitamin E deficiency (Di Mauro et al., 1980; Kennedy et al., 1987). Neurological examination revealed a radial nerve paresis in one calf but no other neurological signs. Because degenerative neuropathy due to vitamin $\mathrm{E}$ deficiency is a disturbance progressing rather slowly, it is conceivable that the animals included in the present study were too young to display clinically apparent neuropathies. It remains uncertain if the various, presumably secondary infectious processes that were diagnosed together with pronounced leukocytosis in all calves are a manifestation of an increased susceptibility to secondary infections resulting from vitamin deficiency remains undetermined. Hypovitaminosis in any case was shown to decrease the resistance to infections in cattle (Spears, 2000; He et al., 2012). The cause for the degenerative changes in the kidney could not be 
determined, different hypoxic or toxic changes lead to similar histopathological changes.

\section{CONCLUSIONS}

We report the occurrence of a new Holstein haplotype of autosomal codominant inheritance that is associated with a severely disturbed cholesterol metabolism with a dramatic effect on health and survival of homozygous haplotype carriers. This congenital defect, termed $\mathrm{CDH}$, is associated with a phenotype characterized by growth retardation, emaciation, and chronic or recurrent diarrhea in calves and shows striking similarities with the human homozygous HHBL. Our results of the whole genome analysis, characteristics of the clinical and blood biochemical phenotype, and similarities between $\mathrm{CDH}$ and HHBL provide additional evidence that $A P O B$, encoding the cholesterol carrier protein Apo B, contains the causal mutation for the previously described cholesterol deficiency in cattle.

\section{ACKNOWLEDGMENTS}

We thank the Förderverein Bioökonomieforschung e.V. (FBF, Bonn, Germany) and Masterrind GmbH for financial support. Masterrind $\mathrm{GmbH}$ is also acknowledged for providing additional affected calves. The authors declare that they have no competing interests.

\section{REFERENCES}

Browning, B. L., and S. R. Browning. 2009. A unified approach to genotype imputation and haplotype-phase inference for large data sets of trios and unrelated individuals. Am. J. Hum. Genet. 84:210-223. http://dx.doi.org/10.1016/j.ajhg.2009.01.005.

Burnett, J. R., and A. J. Hooper. 2015. Vitamin E and oxidative stress in abetalipoproteinemia and familial hypobetalipoproteinemia. Free Radic. Biol. Med. A 88:59-62. http://dx.doi.org/10.1016/j. freeradbiomed.2015.05.044.

Charlier, C. 2016. The role of mobile genetic elements in the bovine genome. Abstract W636 in Plant and Animal Genome XXIV Conference, San Diego, CA.

Charlier, C., J. S. Agerholm, W. Coppieters, P. Karlskov-Mortensen, W. Li, G. de Jong, C. Fasquelle, L. Karim, S. Cirera, N. Cambisano, N. Ahariz, E. Mullaart, M. Georges, and M. Fredholm. 2012. A Deletion in the Bovine FANCI Gene Compromises Fertility by Causing Fetal Death and Brachyspina. PLoS ONE 7:e43085 http://dx.doi.org/10.1371/journal.pone.0043085.

Chen, S. H., C. Y. Yang, P. F. Chen, D. Setzer, M. Tanimura, W. H. Li, A. M. Gotto, and L. Chan. 1986. The complete cDNA and amino acid sequence of human apolipoprotein B-100. J. Biol. Chem. 261:12918-12921.

Correa, M. T., C. R. Curtis, H. N. Erb, and M. E. White. 1988. Effect of calfhood morbidity on age at first calving in New York Holstein herds. Prev. Vet. Med. 6:253-262. http://dx.doi.org/10.1016/01675877(88)90037-2.

DePristo, M. A., E. Banks, R. E. Poplin, K. V. Garimella, J. R. Maguire, C. Hartl, A. A. Philippakis, G. del Angel, M. Rivas, M. Hanna, A. McKenna, T. J. Fennell, A. M. Kernytsky, A. Y. Sivachenko, K. Cibulskis, S. B. Gabriel, D. Altshuler, and M. J. Daly. 2011. A framework for variation discovery and genotyping using next- generation DNA sequencing data. Nat. Genet. 43:491-498. http:// dx.doi.org/10.1038/ng.806.

Di Mauro, S., C. Trevisan, and A. Hays. 1980. Disorders of lipid metabolism in muscle. Muscle Nerve 3:369-388. http://dx.doi. org/10.1002/mus.880030502.

Dickson, S. P., K. Wang, I. Krantz, H. Hakonarson, and D. B. Goldstein. 2010. Rare variants create synthetic genome-wide associations. PLoS Biol. 8:e1000294. http://dx.doi.org/10.1371/journal. pbio.1000294.

Drögemüller, C., J. Tetens, S. Sigurdsson, A. Gentile, S. Testoni, K. Lindblad-Toh, and T. Leeb. 2010. Identification of the bovine arachnomelia mutation by massively parallel sequencing implicates sulfite oxidase (SUOX) in bone development. PLoS Genet. 6:e1001079. http://dx.doi.org/10.1371/journal.pgen.1001079.

Florea, L., A. Souvorov, T. S. Kalbfleisch, and S. L. Salzberg. 2011. Genome assembly has a major impact on gene content: A comparison of annotation in two Bos taurus assemblies. PLoS ONE 6:e21400. http://dx.doi.org/10.1371/journal.pone.0021400.

Freeman, J. L., G. H. Perry, L. Feuk, R. Redon, S. A. McCarroll, D. M. Altshuler, H. Aburatani, K. W. Jones, C. Tyler-Smith, M. E. Hurles, N. P. Carter, S. W. Scherer, and C. Lee. 2006. Copy number variation: New insights in genome diversity. Genome Res. 16:949-961. http://dx.doi.org/10.1101/gr.3677206.

Fritz, S., A. Capitan, A. Djari, S. C. Rodriguez, A. Barbat, A. Baur, C. Grohs, B. Weiss, M. Boussaha, D. Esquerré, C. Klopp, D. Rocha, and D. Boichard. 2013. Detection of haplotypes associated with prenatal death in dairy cattle and identification of deleterious mutations in GART, SHBG and SLC37A2. PLoS ONE 8:e65550. http://dx.doi.org/10.1371/journal.pone.0065550.

Goldstein, D. B. 2009. Common genetic variation and human traits. N. Engl. J. Med. 360:1696-1698. http://dx.doi.org/10.1056/ NEJMp0806284.

Gross, J. J., A.-C. Schwinn, F. Schmitz-Hsu, F. Menzi, C. Drögemüller, C. Albrecht, and R. M. Bruckmaier. 2016. Rapid Communication: Cholesterol deficiency-associated APOB mutation impacts lipid metabolism in Holstein calves and breeding bulls. J. Anim. Sci. 94:1761-1766. http://dx.doi.org/10.2527/jas.2016-0439.

He, X., Y. Li, M. Li, G. Jia, H. Dong, Y. Zhang, C. He, C. Wang, L. Deng, and Y. Yang. 2012. Hypovitaminosis A coupled to secondary bacterial infection in beef cattle. BMC Vet. Res. 8:222 http:// dx.doi.org/10.1186/1746-6148-8-222.

Herzig, C. T., and C. L. Baldwin. 2009. Genomic organization and classification of the bovine WC1 genes and expression by peripheral blood gamma delta T cells. BMC Genomics 10:191. http:// dx.doi.org/10.1186/1471-2164-10-191.

Jansen, S., B. Aigner, H. Pausch, M. Wysocki, S. Eck, A. Benet-Pagès, E. Graf, T. Wieland, T. M. Strom, T. Meitinger, and R. Fries. 2013. Assessment of the genomic variation in a cattle population by re-sequencing of key animals at low to medium coverage. BMC Genomics 14:446. http://dx.doi.org/10.1186/1471-2164-14-446.

Jung, S., H. Pausch, M. C. Langenmayer, H. Schwarzenbacher, M. Majzoub-Altweck, N. S. Gollnick, and R. Fries. 2014. A nonsense mutation in PLD4 is associated with a zinc deficiency-like syndrome in Fleckvieh cattle. BMC Genomics 15:623. http://dx.doi. org/10.1186/1471-2164-15-623.

Kennedy, S., D. A. Rice, and W. B. Davidson. 1987. Experimental myopathy in vitamin E- and selenium-depleted calves with and without added dietary polyunsaturated fatty acids as a model for nutritional degenerative myopathy in ruminant cattle. Res. Vet. Sci. 43:384-394.

Lee, J., and R. A. Hegele. 2014. Abetalipoproteinemia and homozygous hypobetalipoproteinemia: A framework for diagnosis and management. J. Inherit. Metab. Dis. 37:333-339. http://dx.doi. org/10.1007/s10545-013-9665-4.

Lehmbecker, A., S. Rittinghausen, K. Rohn, W. Baumgärtner, and D. Schaudien. 2014. Nanoparticles and pop-off technique for electron microscopy: A known technique for a new purpose. Toxicol. Pathol. 42:1041-1046. http://dx.doi.org/10.1177/0192623313509906.

Li, H., and R. Durbin. 2009. Fast and accurate short read alignment with Burrows-Wheeler transform. Bioinformatics 25:1754-1760. http://dx.doi.org/10.1093/bioinformatics/btp324. 
Li, H., B. Handsaker, A. Wysoker, T. Fennell, J. Ruan, N. Homer, G. Marth, G. Abecasis, R. Durbin, and 1000 Genome Project Data Processing Subgroup. 2009. The Sequence Alignment/Map format and SAMtools. Bioinformatics 25:2078-2079. 10.1093/ bioinformatics/btp352.

Li, Y., C. Sidore, H. M. Kang, M. Boehnke, and G. R. Abecasis. 2011. Low-coverage sequencing: Implications for design of complex trait association studies. Genome Res. 21:940-951. http://dx.doi. org/10.1101/gr.117259.110.

Marcovina, S., and C. J. Packard. 2006. Measurement and meaning of apolipoprotein AI and apolipoprotein B plasma levels. J. Intern. Med. 259:437-446. http://dx.doi.org/10.1111/j.13652796.2006.01648.x.

McClure, M. C., D. Bickhart, D. Null, P. VanRaden, L. Xu, G. Wiggans, G. Liu, S. Schroeder, J. Glasscock, J. Armstrong, J. B. Cole, C. P. Van Tassell, and T. S. Sonstegard. 2014. Bovine exome sequence analysis and targeted SNP genotyping of recessive fertility defects $\mathrm{BH} 1, \mathrm{HH} 2$, and $\mathrm{HH} 3$ Reveal a putative causative mutation in SMC2 for HH3. PLoS ONE 9:e92769. http://dx.doi. org/10.1371/journal.pone.0092769.

Mee, J. F. 2013. Why do so many calves die on modern dairy farms and what can we do about calf welfare in the future? Animals (Basel) 3:1036-1057. http://dx.doi.org/10.3390/ani3041036.

Menzi, F., N. Besuchet-Schmutz, M. Fragnière, S. Hofstetter, V. Jagannathan, T. Mock, A. Raemy, E. Studer, K. Mehinagic, N. Regenscheit, M. Meylan, F. Schmitz-Hsu, and C. Drögemüller. 2016. A transposable element insertion in APOB causes cholesterol deficiency in Holstein cattle. Anim. Genet. 47:253-257. http://dx.doi. org/10.1111/age. 12410 .

Mohd Nor, N., W. Steeneveld, M. C. M. Mourits, and H. Hogeveen. 2012. Estimating the costs of rearing young dairy cattle in the Netherlands using a simulation model that accounts for uncertainty related to diseases. Prev. Vet. Med. 106:214-224. http:// dx.doi.org/10.1016/j.prevetmed.2012.03.004.

Nielsen, R., J. S. Paul, A. Albrechtsen, and Y. S. Song. 2011. Genotype and SNP calling from next-generation sequencing data. Nat. Rev. Genet. 12:443-451. http://dx.doi.org/10.1038/nrg2986.

Olesen, I., A. F. Groen, and B. Gjerde. 2000. Definition of animal breeding goals for sustainable production systems. J. Anim. Sci. 78:570-582.

Pausch, H., H. Schwarzenbacher, J. Burgstaller, K. Flisikowski, C. Wurmser, S. Jansen, S. Jung, A. Schnieke, T. Wittek, and R. Fries. 2015. Homozygous haplotype deficiency reveals deleterious mutations compromising reproductive and rearing success in cattle. BMC Genomics 16:312 http://dx.doi.org/10.1186/s12864$015-1483-7$

Porter, F. D. 2008. Smith-Lemli-Opitz syndrome: Pathogenesis, diagnosis and management. Eur. J. Hum. Genet. 16:535-541. http:// dx.doi.org/10.1038/ejhg.2008.10.

Radostits, O. M., C. C. Gay, K. W. Hinchcliff, and P. D. Constable. 2007. Veterinary Medicine: A Textbook of the Diseases of Cattle, Horses, Sheep, Pigs and Goats, 10th ed. Saunders, Philadelphia, PA.

Saleem, S., C. Heuer, C. Sun, D. Kendall, J. Moreno, and R. Vishwanath. 2016. Technical note: The role of circulating low-density li- poprotein levels as a phenotypic marker for Holstein cholesterol deficiency in dairy cattle. J. Dairy Sci. 99:5545-5550. http://dx.doi. org/10.3168/jds.2015-10805

Santos, R. D., E. J. Schaefer, B. F. Asztalos, E. Polisecki, J. Wang, R. A. Hegele, L. R. C. Martinez, M. H. Miname, C. E. Rochitte, P. L. D. Luz, and R. C. Maranhão. 2008. Characterization of high density lipoprotein particles in familial apolipoprotein A-I deficiency. J. Lipid Res. 49:349-357. http://dx.doi.org/10.1194/jlr. M700362-JLR200.

Spears, J. W. 2000. Micronutrients and immune function in cattle. Proc. Nutr. Soc. 59:587-594.

Tarugi, P., and M. Averna. 2011. Hypobetalipoproteinemia: Genetics, biochemistry, and clinical spectrum. Adv. Clin. Chem. 54:81-107.

Therneau, T. M., and P. M. Grambsch. 2000. Modeling Survival Data: Extending the Cox Model, Statistics for Biology and Health. Springer, New York, NY.

Thorvaldsdóttir, H., J. T. Robinson, and J. P. Mesirov. 2013. Integrative Genomics Viewer (IGV): high-performance genomics data visualization and exploration. Brief. Bioinform. 14:178-192. http:// dx.doi.org/10.1093/bib/bbs017.

VanRaden, P. M., K. M. Olson, D. J. Null, and J. L. Hutchison. 2011. Harmful recessive effects on fertility detected by absence of homozygous haplotypes. J. Dairy Sci. 94:6153-6161. http://dx.doi. org/10.3168/jds.2011-4624.

vit. 2016. Estimation of Breeding Values for Milk Production Traits, Somatic Cell Score, Conformation, Productive Life and Reproduction Traits in German Dairy Cattle. Accessed May 4 2016. http://www.vit.de/fileadmin/user_upload/vit-fuers-rind/ zuchtwertschaetzung/milchrinder-zws-online/Zws_Bes_eng.pdf.

Wang, K., S. P. Dickson, C. A. Stolle, I. D. Krantz, D. B. Goldstein, and H. Hakonarson. 2010. Interpretation of association signals and identification of causal variants from genome-wide association studies. Am. J. Hum. Genet. 86:730-742. http://dx.doi. org/10.1016/j.ajhg.2010.04.003.

Whitfield, A. J., P. H. R. Barrett, F. M. van Bockxmeer, and J. R. Burnett. 2004. Lipid disorders and mutations in the APOB gene. Clin. Chem. 50:1725-1732. http://dx.doi.org/10.1373/ clinchem.2004.038026.

Xi, R., T.-M. Kim, and P. J. Park. 2010. Detecting structural variations in the human genome using next generation sequencing. Brief. Funct. Genomics 9:405-415. http://dx.doi.org/10.1093/ bfgp/elq025.

Yang, J., S. H. Lee, M. E. Goddard, and P. M. Visscher. 2011. GCTA A tool for genome-wide complex trait analysis. Am. J. Hum. Genet. 88:76-82. http://dx.doi.org/10.1016/j.ajhg.2010.11.011.

Yang, J., N. A. Zaitlen, M. E. Goddard, P. M. Visscher, and A. L. Price. 2014. Advantages and pitfalls in the application of mixedmodel association methods. Nat. Genet. 46:100-106. http:// dx.doi.org/10.1038/ng.2876.

Zimin, A. V., A. L. Delcher, L. Florea, D. R. Kelley, M. C. Schatz, D. Puiu, F. Hanrahan, G. Pertea, C. P. V. Tassell, T. S. Sonstegard, G. Marçais, M. Roberts, P. Subramanian, J. A. Yorke, and S. L. Salzberg. 2009. A whole-genome assembly of the domestic cow, Bos taurus. Genome Biol. 10:R42 http://dx.doi.org/10.1186/gb2009-10-4-r42. 